\title{
Cesar Victora, médico epidemiologista. Uma vida de liderança científica mundial a serviço da sobrevivência de milhões de crianças.
}

\section{Cesar Victora, medical epidemiologist. A life of global scientific leadership serving the survival of millions of children.}

\author{
Entrevistadores $^{1}$ : Pedro Rodrigues Cury Hallal$^{2}$ e Fábio Vergara Cerqueira ${ }^{3}$
}

Submetido em 6 e aprovado em 18 de abril de 2018.

O Prof. Victora, por meio de suas pesquisas, é responsável direto pela sobrevivência de milhões de crianças ao redor

do mundo.

Pedro Cury Hallal, Reitor da UFPel.

Somos [o Brasil] um líder mundial em pesquisas sobre desigualdades sociais, e sobre os determinantes sociais do processo saúde-doença. O Canadá também tem muitas pesquisas nestas áreas, especialmente sobre saúde das primeiras nações (first nations). Temos muito que aprender uns com os outros.

Cesar Victora

\section{Apresentação por Pedro Hallal}

O Professor Cesar G. Victora é Professor Emérito da Universidade Federal de Pelotas. Possui graduação em Medicina e doutorado em Epidemiologia da Assistência Médica pela Escola de Higiene e Medicina Tropical da Universidade de Londres. Realizou extensas pesquisas em diversos estados brasileiros, havendo atuado como pesquisador ou consultor em mais de 40 países, assessorando a Organização Mundial da Saúde (OMS) e o UNICEF. Suas principais contribuições científicas incluem a documentação da importância do aleitamento materno exclusivo para prevenir a mortalidade infantil e a construção de curvas de crescimento infantil, atualmente adotadas em mais de 140 países. Foi cofundador do Programa de Pós-Graduação em Epidemiologia da UFPEL, que atualmente tem conceito máximo (grau sete) da CAPES. Atua ainda como Pesquisador nível 1-A do CNPq e Professor Visitante das Universidades de Harvard, Oxford, Londres 
e Johns Hopkins. Recebeu o Prêmio Conrado Wessel de Medicina em 2005 e o Prêmio Scopus/CAPES por produtividade científica em 2006, sendo eleito neste ano para a Academia Brasileira de Ciências e indicado para a Comissão Nacional de Determinantes Sociais em Saúde. Em 2008 recebeu o Prêmio Abraham Horwitz para Liderança em Saúde Inter-Americana, da OPAS; também foi agraciado com o grau de Comendador da Ordem Nacional do Mérito Científico (2008) e da Ordem Nacional do Mérito Médico (2010). Em 2011, recebeu o Prêmio Global de Pesquisa Pediátrica em Denver (USA); em 2013, o Wellcome Trust Senior Investigator Award, com financiamento de sete anos para criar um Observatório Global de Desigualdades em Saúde Materno-Infantil. Foi presidente da Associação Epidemiológica Internacional (período de 2011-14). Foi agraciado com o Canada Gairdner Global Health Award em 2017.

O Prof. Victora, por meio de suas pesquisas, é responsável direto pela sobrevivência de milhões de crianças ao redor do mundo. A promoção da amamentação exclusiva e o monitoramento adequado do crescimento, dois dos legados deixados pelos estudos liderados pelo Prof. Cesar, evitaram e seguem evitando que milhões de crianças percam a vida precocemente. Enquanto não está salvando vidas, o Prof. Cesar passa seu tempo velejando pela Lagoa dos Patos e assistindo a jogos de futebol na televisão. Na condição de Reitor da Universidade Federal de Pelotas, é com muito orgulho que apresento a entrevista com este que, indubitavelmente, é hoje o maior pesquisador do país.

Referência mundial em epidemiologia, liderança em várias projetos globais de pesquisa que salvam milhões de vidas, Cesar Victora acomodou sua agenda, para a entrevista cedida à Interfaces. Foi durante um voo para os Estados Unidos, no dia 04 de abril, que respondeu às questões elaboradas pelo Prof. Pedro Cury Hallal, Reitor da UFPel e antigo orientando do professor Victora, e pelo Prof. Fábio Vergara Cerqueira, professor titular do Departamento de História da UFPel e editor-adjunto da Interfaces. 
(FVC) Em 2017, foste condecorado com o Prêmio Gairdner no Canadá. Qual a importância internacional deste prêmio? Qual sua importância para o Brasil? E, do ponto de vista pessoal, o que significa este prêmio para ti?

(C.V.) O Gairdner é um dos prêmios mais respeitados na área de ciências da saúde em nível mundial. É uma premiação extremamente prestigiosa, os cientistas agraciados em anos anteriores são profissionais de altíssimo nível, mundialmente famosos. Ter sido o primeiro pesquisador brasileiro a ser premiado me deixa particularmente feliz. Pessoalmente, foi uma surpresa. Eu sabia que havia sido indicado pela Dr. ${ }^{\text {a }}$ Nubia Muñoz, que descobriu a relação entre o vírus HPV e o câncer de colo uterino, e foi contemplada com o prêmio em 2009. Mas sabia também que a competição seria acirrada, tendo em vista a qualificação dos nomeados. Creio que esse prêmio reflete o crescimento da ciência brasileira nos últimas duas ou três décadas, com investimento das agências nacionais e estaduais de financiamento, que tiveram papel decisivo na criação de uma grande comunidade científica dentro da saúde coletiva. Foi um progresso impressionante desde os anos 1970-1980, quando a epidemiologia começou a se desenvolver em nosso meio científico. E, finalmente, a premiação também reflete o trabalho de equipe que realizamos aqui, na Universidade Federal de Pelotas. É um reconhecimento para todo um grupo, mais do que para um indivíduo.

(FVC) Qual a importância do Canadá na sua carreira como pesquisador e nos estudos que desenvolves?

(C.V.) O Canadá teve importância fundamental em minhas pesquisas. Foi uma agência canadense, o International Development Research Centre (IDR), que nos concedeu o financiamento para a realização do primeiro acompanhamento da Coorte de Nascimentos de 1982 em Pelotas, numa época em que a epidemiologia ainda engatinhava no Brasil e um estudo desse porte parecia inviável. Hoje, é o maior e mais longo estudo do gênero em andamento fora dos EUA e Europa. O IDRC também financiou a minha pesquisa pioneira sobre o aleitamento materno exclusivo, que resultou em mudanças nas recomendações globais sobre como crianças pequenas devem ser alimentadas. 
(PH) Como analisas a importância da internacionalização na pesquisa cientifica, especialmente para o Brasil?

(C.V.) A internacioanalização é uma tendência crescente e irreversível. No Centro Internacional de Equidade em Saúde aqui em Pelotas (www.equidade.org) produzimos análises sobre mais de uma centena de países de renda média e baixa, com colaborações intensas com pesquisadores destes países. Fazemos também parte de vários consórcios internacionais de pesquisas epidemiológicas, particularmente sobre estudos de coortes de nascimentos.

(PH) Qual a sua visão sobre o êxodo recente de pesquisadores e estudantes brasileiros para o exterior?

(C.V.) Vejo isso com muita tristeza e preocupação. Para se ter uma ideia, somente no ano passado, três integrantes altamente qualificados de minha equipe foram recrutados por universidades inglesas, e agora um quarto pesquisador está emigrando para a Austrália. São pesquisadores jovens, em que o Brasil investiu em formação e, agora, estão desenvolvendo pesquisas de ponta no exterior. Isso porque, com cortes de bolsas e restrições orçamentárias, não temos como oferecer as condições para mantê-los aqui. Infelizmente, mudanças recentes nas políticas federais nas áreas de saúde e de ciência e tecnologia estão colocando em risco todo um esforço de qualificação da pesquisa brasileira desenvolvido nas últimas décadas. Comparativamente com outros países, o Brasil investe um percentual baixo do PIB. É menor do que a média dos outros países. Teríamos, portanto, que aumentar mais rapidamente o investimento se quiséssemos alcançar o nível dos Estados Unidos e da Europa. Vejo o momento atual com muito receio, pois toda a continuidade do progresso científico do país está ameaçada por cortes orçamentários.

(PH) Quais as principais qualidades e desvantagens do modelo de financiamento à ciência e tecnologia no Brasil?

(C.V.) Após um crescimento marcado durante duas décadas, a ciência e tecnologia brasileiras estão ameaçadas por um governo míope, que não entende que pesquisa é um 
investimento e não uma despesa. Atualmente, vejo com muita preocupação o futuro de nossa ciência.

(FVC) O que Brasil e Canadá teriam a aprender um com o outro em termos de sistema universitário e de ciência?

(C.V.) $\mathrm{Na}$ minha área de atuação, a Saúde Coletiva, o Brasil é um exemplo de pesquisa engajada em melhorar as condições de vida da população, em particular dos grupos populacionais mais pobres e excluídos, como a população afrodescendente e indígena. Somos um líder mundial em pesquisas sobre desigualdades sociais, e sobre os determinantes sociais do processo saúde-doença. O Canadá também tem muitas pesquisas nestas áreas, especialmente sobre saúde das primeiras nações (First Nations). Temos muito que aprender uns com os outros.

(FVC) Em que áreas vês potencial e oportunidades maiores de cooperação acadêmica e científica entre Brasil e Canadá?

(C.V.) Além da área de desigualdades sociais e étnicas, temos amplas possibilidades de colaborar na pesquisa sobre metodologia epidemiológica, epidemiologia clínica (o Canadá é um pioneiro nesta área, especialmente em termos de rastreamento (screening) para doenças, e planejamento e integração de redes de serviços de saúde). Temos também a característica de sermos países com sistemas unificados de saúde, que atendem a toda a população independente de sua posição social. Pesquisas sobre como aprimorar nossos sistemas constituem também uma importante área para colaboração.

\section{Notas}

\footnotetext{
${ }^{1}$ Os dois entrevistadores formularam e apresentaram perguntas. Pedro Hallal redigiu a apresentação.

${ }^{2}$ Reitor da Universidade Federal de Pelotas (UFPel). Doutorado (2005) em Epidemiologia pela UFPel. Professor do Programa de Pós-Graduação em Educação Física e em Epidemiologia. Sócio fundador e expresidente da Sociedade Brasileira de Educação Física e Saúde. Bolsista Produtividade do CNPq. Brasil, Rio Grande do Sul, Pelotas. prchallal@gmail.com.

3 Bolsista Produtividade do CNPq. Pesquisador Humboldtiano. Doutor em Antropologia Social (USP). Professor do Programa de Pós-Graduação em História e do Programa de Pós-Graduação em Memória Social e Patrimônio Cultural da UFPel. Brasil, Rio Grande do Sul, Pelotas. fabiovergara@uol.com.br.
} 


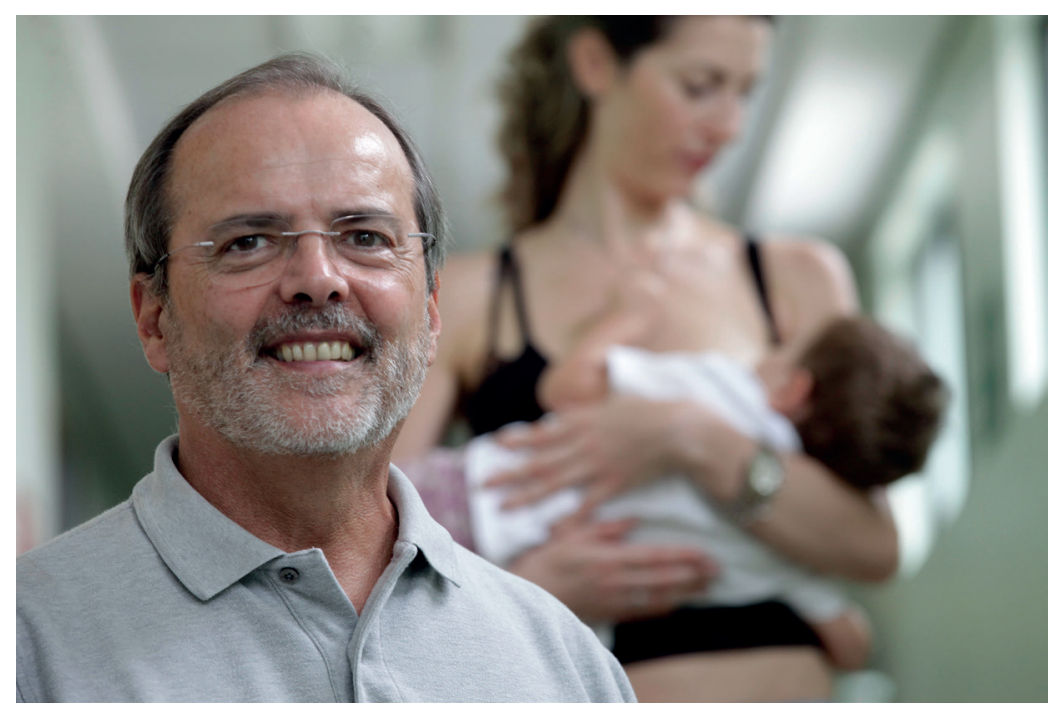

Prof. Cesar Victora

Foto: Daniela Xu/CPE (Centro de Pesquisas Epidemiológicas) 